\title{
Is there a role for the adaptive immune system in pancreatic beta cell failure in type 2 diabetes?
}

\author{
Clara Westwell-Roper • Jan A. Ehses
}

Received: 25 November 2013 / Accepted: 4 December 2013 /Published online: 21 December 2013

(C) Springer-Verlag Berlin Heidelberg 2013

\begin{abstract}
Pancreatic beta cell failure dictates the clinical onset of type 2 diabetes, with insulin secretion insufficient to overcome peripheral tissue insulin resistance. Over the past 5-10 years, a convincing case has emerged supporting the contribution of islet inflammation to this beta cell failure. IL-1 is central to this insult, impairing insulin secretion in preclinical and clinical studies. Further, islet-infiltrating macrophages are a major source of IL-1 and other cytokines in response to elevated levels of nutrients (glucose, saturated fatty acids), endocannabinoids and islet amyloid polypeptide (IAPP). In this issue of Diabetologia, Butcher et al have further characterised immune cell subsets present in islets from individuals with type 2 diabetes (DOI: 10.1007/s00125-0133116-5). Increased numbers of $\mathrm{CD} 45^{+}$leucocytes were found in these islets compared with islets from healthy controls, with an elevated proportion of $\mathrm{CD} 20^{+} \mathrm{B}$ cells within the $\mathrm{CD} 45^{+}$population. Their data also suggest that absolute numbers of $\mathrm{CD}^{+} \mathrm{T}$ cells and $\mathrm{CD} 11 \mathrm{~b}^{+} \mathrm{CD} 11 \mathrm{c}^{+}$ myeloid cells may be increased in islets from individuals with type 2 diabetes. While many aspects of islet inflammation await further exploration, the study from Butcher and colleagues suggests a role for immune cellmediated inflammation early in disease pathogenesis, and supports the concept that targeting the immune system may slow continued beta cell demise in type 2 diabetes.
\end{abstract}

\footnotetext{
C. Westwell-Roper

Department of Pathology and Laboratory Medicine, Faculty of Medicine, Child \& Family Research Institute, University of British Columbia, Vancouver, BC, Canada

J. A. Ehses $(\bowtie)$

Department of Surgery and Cellular and Physiological Sciences, Faculty of Medicine, Child \& Family Research Institute, University of British Columbia, Room A4-183, 950W 28th Ave, Vancouver, BC, Canada V5Z 4H4

e-mail: ehses@mail.ubc.ca
}

Keywords B cells · Inflammasome · Inflammation · Insulin · Interleukin-1 · Macrophage $\cdot$ Pancreatic beta cell $\cdot$ Pancreatic islet $\cdot$ T cells $\cdot$ Type 2 diabetes
Abbreviations
HFD High-fat diet
hIAPP Human islet amyloid polypeptide
IAPP Islet amyloid polypeptide
IL-1Ra IL-1 receptor antagonist
IEQs Islet equivalents

World Diabetes Day on November 14, 2013 once again highlighted the global health and economic impact of this disease. Current estimates indicate that 382 million people are living with diabetes, and 592 million are predicted to be diagnosed with diabetes by 2035 [1]. These statistics are frightening, considering that - only 10 years ago - the International Diabetes Federation predicted that 333 million people would be diagnosed with the condition by 2025 [2], a figure that has now been surpassed.

Ninety per cent of diabetic individuals have type 2 diabetes, which is a complex disease resulting from the interaction between predisposing genes and an unhealthy environment. Clinical onset occurs when pancreatic beta cells fail in the face of insulin resistance, which is likely to be due to a combination of impaired insulin secretion and reduced beta cell mass [3]. Several mechanisms have been proposed to explain this failure, with recent attention falling on a chronic inflammatory process deleterious to beta cell insulin secretion [4].

It has long been appreciated that chronic activation of the innate immune system is associated with type 2 diabetes [5, 6]. Preclinical evidence now suggests that many organs 
critical to the regulation of glucose homeostasis, including the pancreatic islets of Langerhans, show signs of a chronic inflammatory process. Analysis of human tissue has indicated the presence of infiltrating $\mathrm{CD} 68^{+}$macrophages in islets in individuals with type 2 diabetes [7,8], together with increased expression of macrophage chemoattractants (CCL2, CCL13) in laser-captured beta cells [9]. Increased expression of IL-1 $\beta$ has also been found in autopsy pancreases from type 2 diabetic individuals [10]. Indeed, recent clinical trials targeting IL-1 have confirmed that inflammation contributes to beta cell failure in humans with this disease. These include our original study of the IL-1 receptor antagonist (IL-1Ra) in type 2 diabetes [11], industry sponsored studies using IL-1 $\beta$ specific antibodies [12] and a recent clinical study in nondiabetic volunteers with the metabolic syndrome [13]. The latter study showed that IL-1Ra improved measures of beta cell function with no effect on insulin resistance as assessed by hyperinsulinaemic-euglycaemic clamping [13], supporting our observations [11]. Because beta cell dysfunction can precede the clinical onset of type 2 diabetes, this suggests a very early role for IL-1-driven beta cell dysfunction in type 2 diabetes. It also confirms the islet-specific role of IL-1 in this disease, perhaps due to inflammasome activation by isletlocalised amyloid deposits $[14,15]$ and/or high sensitivity of the beta cell to IL-1 due to high IL-1 receptor expression [16].

Despite these advances, there remain a number of unanswered questions with respect to the contribution of immune cells to beta cell function in type 2 diabetes. What are the phenotypes of resident and infiltrating islet macrophages in type 2 diabetes? Are other innate or adaptive immune cells involved in the regulation of beta cell function? Some of these questions have started to be addressed in rodent models of type 2 diabetes. An elegant study by Eguchi and colleagues recently demonstrated that infusion of ethyl palmitate in mice impaired beta cell function via toll-like receptor 4 (TLR4) signalling [17]. This study also showed a direct contribution of macrophages to beta cell dysfunction. Proinflammatory M1 macrophages were recruited to islets in mice infused with ethyl palmitate, in the $d b / d b$ mouse, and in the KKAy mouse. Macrophage depletion in vivo in all these models increased Ins and $P d x I$ mRNA expression in islets and increased glucose-stimulated insulin secretion in vivo and in isolated islets ex vivo [17].

In another recent study, Jourdan and colleagues found higher levels of endocannabinoids in islets of the Zucker diabetic fatty rat compared with islets from lean rats [18]. Peripheral CB1 cannabinoid receptor blockade reduced islet inflammation and improved beta cell insulin secretion with no effects on insulin resistance, as confirmed by hyperinsulinaemic-euglycaemic clamping. Macrophage depletion in vivo in Zucker diabetic fatty rats paralleled these effects, and macrophage-specific CB1 receptor deletion confirmed the role of this receptor in the deleterious effects of proinflammatory macrophages on beta cells [18].
Finally, recent work led by us confirmed that transgenic mice expressing human islet amyloid polypeptide (hIAPP) in beta cells have increased IL-1 $\beta$ expression in their islets, localised to macrophages [15]. hIAPP, which aggregates to form islet amyloid deposits in type 2 diabetes (unlike the nonamyloidogenic rodent form), was recently identified as a novel activator of the NOD-, LRR- and pyrin domaincontaining protein (NLRP3) inflammasome (a multi-protein complex that generates active IL- $1 \beta$ from pro-IL- $1 \beta$ ) in macrophages and dendritic cells [14]. However, only when transgenic mice expressing hIAPP in beta cells were fed a high-fat diet (HFD) did beta cell dysfunction become evident. This was associated with increased islet macrophage IL- $1 \beta$ expression in the face of reduced IL-1Ra expression, the latter due to HFD feeding [15]. Depletion of resident islet macrophages in vivo reduced islet IL-1 $\beta$ expression, improved beta cell insulin secretion as measured in isolated islets, and improved glucose tolerance in these mice [15]. Macrophage depletion also improved glycaemia and reduced islet IL- $1 \beta$ expression in hIAPP transgenic mice with insulin resistance and obesity caused by expression of the agouti viable yellow allele [15] Thus, IAPP-activated islet macrophages are directly linked to beta cell dysfunction in mice with features of type 2 diabetes. Overall, these publications strongly implicate islet macrophages as critical mediators of beta cell dysfunction in type 2 diabetes.

However, rodent models of disease are no substitute for human tissue, and in this issue of Diabetologia, Butcher and colleagues performed the most definitive characterisation to date of the types of immune cell that are present in the islets of humans with type 2 diabetes [19]. The availability of human islet preparations from individuals with type 2 diabetes is very limited, making it difficult to understand the pathophysiology underlying beta cell failure in this disease. In this study, human islets isolated from 21 individuals without diabetes were compared with those from 18 individuals with type 2 diabetes, an impressive sample size well matched for islet purity and clinical characteristics other than BMI (age, sex, race, cause of death). Impaired glucose-stimulated insulin secretion in islets from individuals with type 2 diabetes was confirmed by islet perifusion, and increased $T N F$ and CCL2 mRNA expression was found at the whole islet level, correlating with severely impaired beta cell function. Interestingly, expression of ALOX12 mRNA, encoding 12-lipoxygenase (an enzyme that catalyses oxygenation of arachidonic acid in the eicosanoid synthesis pathway), was only increased in islets demonstrating mild impairments in insulin secretion.

Investigation of total leucocyte numbers indicated that approximately twofold more $\mathrm{CD} 45^{+}$leucocytes were present per 1,000 islet equivalents (IEQs) in islets from individuals with type 2 diabetes. $\mathrm{CD} 45^{+}$cell number positively correlated with beta cell function and $A L O X 12$ expression, and not with 
BMI, CCL2, or TNF expression. Further analysis of immune cell subtypes showed that islets have resident myeloid

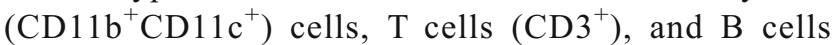
$\left(\mathrm{CD} 20^{+}\right)$. Most islet leucocytes were $\mathrm{T}$ cells $(\sim 25-30 \%$ of CD $45^{+}$cells), followed by CD11b ${ }^{+}$myeloid cells $(\sim 15 \%$ of CD $45^{+}$cells), followed by B cells $\left(\sim 2.5 \%\right.$ of CD $45^{+}$cells). The percentages (of CD $45^{+}$cells) of $\mathrm{CD}^{+} \mathrm{T}$ cells, CD11 ${ }^{+}$

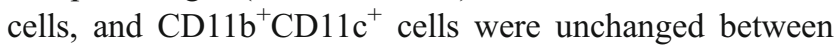
groups. $\mathrm{CD}^{+} 8^{+}$macrophages were not assessed, so it is unclear what proportion of $\mathrm{CD} 11 \mathrm{~b}^{+}$cells were $\mathrm{CD}^{+} 8^{+}$, or if

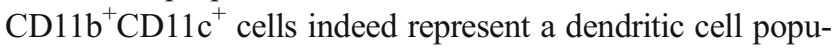
lation that is $\mathrm{CD}^{-}$. However, a 2.2-fold increase in the proportion of $\mathrm{CD}_{20} 0^{+} \mathrm{B}$ cells relative to $\mathrm{CD} 45^{+}$cells was found in islets from individuals with type 2 diabetes.

A number of interesting observations are worth highlighting from this study. First, CD $45^{+}$leucocytes and ALOX12 expression were increased in islets showing mild rather than severe beta cell impairment. This suggests a role for immune cell-mediated inflammation early in disease pathogenesis, and supports the clinical findings of van Asseldonk and colleagues [13] and our initial observations in the HFD-fed mouse [7]. It also highlights the dynamic nature of tissue inflammation. The nature and extent of the inflammatory response depend on numerous factors including time of disease onset, age, genetics, sex and the state of beta cell function. With respect to this, longitudinal studies on islet inflammation in rodent models of this disease will be informative. Indeed, if greater numbers of human islet samples become available, together with associated clinical history, it will be helpful to correlate islet function and inflammation (including immune cell subtypes, activation state and function) with duration of disease, medication and autoantibody status.

Second, because total $\mathrm{CD}^{+} 5^{+}$cells/1,000 IEQs were increased (with a change in proportion noted only for B cells, which comprise $\sim 2.5 \%$ of $\mathrm{CD} 45^{+}$cells and do not account for the total increase in this population), absolute numbers of $\mathrm{T}$ cells, macrophages/dendritic cells and B cells all appear to be increased in islets from donors with type 2 diabetes, with possible contributions from other uncharacterised haematopoietic cells such as granulocytes, natural killer (NK) cells and other innate lymphoid cells. The greatest increase was seen in B cells. Thus, in addition to the well-supported role of macrophages in beta cell failure in type 2 diabetes, the study by Butcher and colleagues suggests a role for B cells (and potentially T cells and other myeloid cells) in the pathophysiology of this disease. B cells were found to induce insulin resistance during diet-induced obesity in mice [20]. Recent human data showed that circulating $B$ cells are hyperactivated in individuals with type 2 diabetes and elicit $\mathrm{T}$ cell-derived proinflammatory IL-17 production in T cell/B cell co-cultures via contactdependent mechanisms [21]. Monocytes are also required to maintain the proinflammatory Th17 signature in type 2 diabetes [22]. Interestingly, increased numbers of circulating $\mathrm{T}$ cells reactive to islet proteins are detectable in some individuals with type 2 diabetes [23]. Whether islet B cells (or macrophages) also regulate proinflammatory cytokine production by islet $\mathrm{T}$ cells, or affect other features of islet $\mathrm{T}$ cell activation in type 2 diabetes, awaits investigation. Indeed, further characterisation of the activation state of macrophages (M1 vs M2), and $\mathrm{T}$ and $\mathrm{B}$ cells, is warranted in addition to further classification and functional analyses of immune cell subsets (e.g. naive vs memory $\mathrm{CD}^{+} / \mathrm{CD}^{+} \mathrm{T}$ cells, regulatory T cells [Tregs], B1 vs $\mathrm{B} 2$ cells, plasma cells and regulatory B cells). Finally, information regarding the antigen specificity of $\mathrm{T}$ and $\mathrm{B}$ cell receptors within the islets will be important. Such characterisation will be critical to determining whether increases in specific immune cell subsets represent an adaptive response to islet damage rather than an instigation of an inflammatory response.

The study by Butcher and colleagues has highlighted some intriguing changes in innate and adaptive immune cell types in islets in type 2 diabetes; however, we are at the tip of the iceberg with respect to understanding the inflammatory process ongoing in islets in this disease. It is hoped that further characterisation of islet inflammation will lead to novel targeted therapies to help prevent the decline of beta cell mass and function in type 2 diabetes.

Acknowledgements We thank all members of the Ehses laboratory (University of British Columbia) for their insightful comments and feedback.

Funding Funding for work at the Ehses laboratory is provided by the Child \& Family Research Institute, the University of British Columbia, the Canadian Foundation for Innovation, the Canadian Diabetes Association, the Canadian Institutes of Health Research and Servier. JAE has salary support from a Child and Family Research Institute investigator award and a Canadian Diabetes Association scholar award. CWR is supported by a CIHR-Vanier Canada Graduate Scholarship.

Duality of Interest The authors declare that there is no duality of interest associated with this manuscript.

Contribution statement JAE was responsible for the conception and design of the manuscript. Both authors were involved in drafting the article, revising it critically for important intellectual content, and approved the version to be published.

\section{References}

1. International Diabetes Federation (2013) IDF diabetes atlas, 6th edn. International Diabetes Federation, Brussels, Belgium

2. International Diabetes Federation (2003) IDF diabetes atlas, 2nd edn. International Diabetes Federation, Brussels, Belgium

3. Kahn SE, Zraika S, Utzschneider KM, Hull RL (2009) The beta cell lesion in type 2 diabetes: there has to be a primary functional abnormality. Diabetologia 52:1003-1012

4. Donath MY, Shoelson SE (2011) Type 2 diabetes as an inflammatory disease. Nat Rev Immunol 11:98-107

5. Pickup JC, Crook MA (1998) Is type II diabetes mellitus a disease of the innate immune system? Diabetologia 41:1241-1248 
6. Wellen KE, Hotamisligil GS (2005) Inflammation, stress, and diabetes. J Clin Invest 115:1111-1119

7. Ehses JA, Perren A, Eppler E et al (2007) Increased number of isletassociated macrophages in type 2 diabetes. Diabetes 56:2356-2370

8. Richardson SJ, Willcox A, Bone AJ, Foulis AK, Morgan NG (2009) Islet-associated macrophages in type 2 diabetes. Diabetologia 52: $1686-1688$

9. Igoillo-Esteve M, Marselli L, Cunha DA et al (2010) Palmitate induces a pro-inflammatory response in human pancreatic islets that mimics CCL2 expression by beta cells in type 2 diabetes. Diabetologia 53:1395-1405

10. Maedler K, Sergeev P, Ris F et al (2002) Glucose-induced beta cell production of IL-1 beta contributes to glucotoxicity in human pancreatic islets. J Clin Invest 110:851-860

11. Larsen CM, Faulenbach M, Vaag A et al (2007) Interleukin-1receptor antagonist in type 2 diabetes mellitus. N Engl J Med 356: $1517-1526$

12. Donath MY, Dalmas E, Sauter NS, Boni-Schnetzler M (2013) Inflammation in obesity and diabetes: islet dysfunction and therapeutic opportunity. Cell Metab 17:860-872

13. van Asseldonk EJ, Stienstra R, Koenen TB, Joosten LA, Netea MG, Tack CJ (2011) Treatment with Anakinra improves disposition index but not insulin sensitivity in nondiabetic subjects with the metabolic syndrome: a randomized, double-blind, placebo-controlled study. J Clin Endocrinol Metab 96:2119-2126

14. Masters SL, Dunne A, Subramanian SL et al (2010) Activation of the NLRP3 inflammasome by islet amyloid polypeptide provides a mechanism for enhanced IL-1beta in type 2 diabetes. Nat Immunol 11:897-904

15. Westwell-Roper CY, Ehses JA, Verchere CB (2013) Resident macrophages mediate islet amyloid polypeptide-induced islet IL-1beta production and beta cell dysfunction. Diabetes. doi:10.2337/db130863

16. Boni-Schnetzler M, Thorne J, Parnaud G et al (2008) Increased interleukin (IL)-1beta messenger ribonucleic acid expression in beta -cells of individuals with type 2 diabetes and regulation of IL-1 beta in human islets by glucose and autostimulation. J Clin Endocrinol Metab 93:4065-4074

17. Eguchi K, Manabe I, Oishi-Tanaka Y et al (2012) Saturated fatty acid and TLR signaling link beta cell dysfunction and islet inflammation. Cell Metab 15:518-533

18. Jourdan T, Godlewski G, Cinar R et al (2013) Activation of the Nlrp3 inflammasome in infiltrating macrophages by endocannabinoids mediates beta cell loss in type 2 diabetes. Nat Med 19:1132-1140

19. Butcher MJ, Hallinger D, Garcia E et al (2013) Association of proinflammatory cytokines and islet resident leucocytes with islet dysfunction in type 2 diabetes. Diabetologia. doi:10.1007/s00125013-3116-5

20. Winer DA, Winer S, Shen L et al (2011) B cells promote insulin resistance through modulation of T cells and production of pathogenic IgG antibodies. Nat Med 17:610-617

21. DeFuria J, Belkina AC, Jagannathan-Bogdan M et al (2013) B cells promote inflammation in obesity and type 2 diabetes through regulation of T-cell function and an inflammatory cytokine profile. Proc Natl Acad Sci U S A 110:5133-5138

22. Jagannathan-Bogdan M, McDonnell ME, Shin H et al (2011) Elevated proinflammatory cytokine production by a skewed $\mathrm{T}$ cell compartment requires monocytes and promotes inflammation in type 2 diabetes. J Immunol 186:1162-1172

23. Brooks-Worrell B, Narla R, Palmer JP (2013) Islet autoimmunity in phenotypic type 2 diabetes patients. Diabetes Obes Metab 15(Suppl 3):137-140 